\title{
Sorption of rare earth coordination compounds
}

\author{
Olga V. CHEREMISINA ${ }^{1}$, Elizaveta CHEREMISINA ${ }^{2}$, Maria A. PONOMAREVA ${ }^{1}$, Aleksander T. FEDOROV ${ }^{1}$ \\ ${ }^{1}$ Saint Petersburg Mining University, Saint Petersburg, Russia \\ ${ }^{2}$ K1-MET GmbH, Linz, Austria
}

How to cite this article: Cheremisina O.V., Cheremisina E., Ponomareva M.A., Fedorov A.T. Sorption of rare earth coordination compounds. Journal of Mining Institute. 2020. Vol. 244, p. 474-481. DOI: 10.31897/PMI.2020.4.10

\begin{abstract}
Rare earth elements (REEs) are valuable and strategically important in many high-technology areas, such as laser technology, pharmacy and metallurgy. The main methods of REE recovery are precipitation, extraction and sorption, in particular ion exchange using various sorbents, which allow to perform selective recovery and removal of associated components, as well as to separate rare earth metals with similar chemical properties. The paper examines recovery of ytterbium in the form of coordination compounds with Trilon B on weakly basic anion exchange resin D-403 from nitrate solutions. In order to estimate thermodynamic sorption parameters of ytterbium anionic complexes, ion exchange process was carried out from model solutions under constant ionic strength specified by $\mathrm{NaNO}_{3}$, optimal liquid to solid ratio, $\mathrm{pH}$ level, temperatures 298 and $343 \mathrm{~K}$ by variable concentrations method. Description of thermodynamic equilibrium was made using mass action law formulated for ion exchange equation and mathematically converted to linear form. Values of equilibrium constants, Gibbs free energy, enthalpy and entropy of the sorption process have been calculated. Basing on calculated values of Gibbs energy, a sorption series of complex REE ions with Trilon B was obtained over anion exchange resin D-403 from nitrate solutions at temperature $298 \mathrm{~K}$. Sorption characteristics of anion exchange resin have been estimated: total capacity, limiting sorption of complex ions, total dynamic capacity and breakthrough dynamic capacity.
\end{abstract}

Key words: thermodynamics of sorption and ion exchange; equilibrium constant; Gibbs free energy of ion exchange equilibrium; ytterbium; rare earth metals

\begin{abstract}
Acknowledgements: This research has been performed as a part of the project N 19-19-00377 "Technological Foundations of Extraction and Selection of Strategically Significant Rare Earth Elements from Products of Apatite Processing", supported by the Russian Science Foundation in 2019 contest "Basic Scientific Research and Exploratory Scientific Research, Conducted by Individual Research Teams" of 22.04.2019.
\end{abstract}

Introduction. Rare earth metals (REMs) are an integral part of many high-technology industrial sectors, such as laser technology, military equipment, pharmacy, electronics, metallurgy and automobile industry.

As a result of REM market analysis, a conclusion can be drawn that in 2014-2017 REM extraction rate was relatively stable, and starting from 2018 it dramatically increased from 132 to 170 thousand tons [3]. In terms of resources, the key leader of the last decade still is China with a market share of $37.89 \%$, Brazil and Vietnam follow with equal shares of $18.94 \%$. Russia is also not the last country on this list with a share of $10.33 \%$. Other countries worth mentioning are Australia, the USA, Malaysia and India, which also have estimated REM reserves [3].

Presently Russia does not produce but rather imports rare earth elements (REEs), which negatively affects the economy of the country and its industrial sector in particular.

The main target source of REEs in Russia is located in Murmansk oblast, at Lovozero deposit. There is also associated extraction of REMs as a component of other ores and waste products $[6,15$, 16]. However, in Russia there are no deep processing facilities, so it impossible to obtain the final product in the form of individual REMs. As a result, extracted REMs are exported as cheap collective concentrates.

The main methods of REE recovery are precipitation, extraction, and sorption [5, 8, 12, 13, 18$]$. Sorption processes are the most promising method of selective REM recovery from multisalt solutions, which allows to separate elements from their associated components, as well as to separate REMs with similar chemical properties [10]. 
Authors of paper [7] studied recovery of $\mathrm{Nd}, \mathrm{Gd}$ and Ho on synthesized resins, the functional group of which is represented by primary amine surface groups with REM-binding ligands: phosphonoacetic acid (PAA), N, N-bis (phosphonomethyl) glycine (BPG) and diethylenetriaminepentaacetic dianhydride (DTPADA). In order to estimate thermodynamic characteristics, a series of tests was performed with solutions, containing $0.3-300 \mathrm{mg} / \mathrm{l}$ of REEs at constant $\mathrm{HCl}$ concentration of $0.5 \mathrm{~mol} / 1$ and a fixed $\mathrm{pH}$ value. Solutions were mixed at $300 \mathrm{rpm}$ for 24 hours with ion exchange resin $(10 \mathrm{~g} / \mathrm{l})$ at three temperatures: 20,60 and $100^{\circ} \mathrm{C}$. Sorption isotherms were obtained in constant presence of $\mathrm{NaCl}(0.5 \mathrm{~mol} / \mathrm{l})$ and fixed $\mathrm{pH}$ values, dependent on synthesized anion resin: 6.5 for amine, PAA, BPG or 2.5 for DTPADA, at temperatures 20,60 and $100{ }^{\circ} \mathrm{C}$. Thermodynamic description was made using Langmiur and Freundlich models. As a result, the authors calculated values of equilibrium constants, Gibbs free energy, enthalpy and entropy of $\mathrm{Nd}$, Gd and Ho extraction.

In paper [14] the authors examined separation of metals based on ion exchange displacement of metal ions (Se, Re, Mo, La, Sc, Ce (IV)) from the solid phase on ion exchange resins Purolite A170, Lewatit M500 and Lewatit SP112. Effective separation of cerium (IV) and lanthanum was observed on Lewatit MonoPlus SP $112\left(\mathrm{Na}^{+}\right)$. Ion exchanger saturation was conducted under dynamic conditions with a lanthanum nitrate solution. Then elution with cerium (IV) nitrate solution was carried out. In the course of experiment, it was observed that cerium (IV) displaced 96-97\% of lanthanum from the solid phase of the resin. The process of frontal-gradient displacement of lanthanum by cerium (IV) was a part of the developed technology. Total coefficient of cerium and lanthanum separation using designed extraction method was 4300. Distribution coefficients for cerium and lanthanum were 1000 and 0.23 , respectively. This method allows to extract cerium (IV) with the purity of $99.9 \%$.

Likewise, for extraction of such metals as thorium (IV) and uranium (IV) in the study [17] authors used solid sorbents with a resin matrix in the form of monomer 2, 4, 6-triformylphloroglucine and 2,5-diaminobenzenesulfonic acid (COF) and functional groups $\mathrm{COF}-\mathrm{SO}_{3} \mathrm{H}$ and $\left[\mathrm{NH}_{4}\right]^{+}\left[\mathrm{COF}-\mathrm{SO}_{3}^{-}\right]$. The paper estimates the impact of $\mathrm{pH}$ on thorium (IV) sorption capacity in the interval 1-2.8. A conclusion was drawn that for sorbent $\left[\mathrm{NH}_{4}\right]^{+}\left[\mathrm{COF}-\mathrm{SO}_{3}^{-}\right]$with the growth of $\mathrm{pH}$ its capacity increased from $98.8(\mathrm{pH}=1)$ to $168 \mathrm{mg} / \mathrm{g}(\mathrm{pH}=2.8)$. A similar tendency was observed for sorbent COF$\mathrm{SO}_{3} \mathrm{H}$; however, a decrease in $\mathrm{pH}$ level resulted in declining capacity values. Research on kinetic dependencies demonstrated that within 10 minutes of the experiment capacity value reached $232 \mathrm{mg} / \mathrm{g}$ from the solution with thorium (IV) concentration of $125 \mathrm{ppm}$ at $\mathrm{pH}=2.8$ on the sorbent $\left[\mathrm{NH}_{4}\right]^{+}\left[\mathrm{COF}-\mathrm{SO}_{3}^{-}\right]$and $100 \mathrm{mg} / \mathrm{g}$ on the sorbent $\mathrm{COF}-\mathrm{SO}_{3} \mathrm{H}$. Sorption isotherms obtained in the interval of concentrations 50-400 ppm were analyzed using Langmuir model. Resulting capacity value was higher for sorbent $\left[\mathrm{NH}_{4}\right]^{+}\left[\mathrm{COF}-\mathrm{SO}_{3}^{-}\right]$than it was for $\mathrm{COF}-\mathrm{SO}_{3} \mathrm{H}$. The authors separated thorium (IV), uranium (IV), cerium (III) and europium (III) and obtained the following coefficients of element separation: $\mathrm{S}_{\mathrm{Th} / \mathrm{U}}=9.4, \mathrm{~S}_{\mathrm{Th} / \mathrm{Eu}}=9.4$ and $\mathrm{S}_{\mathrm{Th} / \mathrm{Ce}}=10.3$.

Problem statement. Analysis of literature references allows to come to a conclusion that REM recovery from multisalt systems [11] is a relevant topic due to the complex character of REM sources. Values of obtained thermodynamic characteristics of the sorption process, namely of ion exchange, define not only conditions of running the process but also technological parameters of ion exchangers for REE separation and removal of associated components. Basing on Gibbs free energy of ion exchange process, it is possible to predict the efficiency of lanthanide recovery from aqueous salt solutions. Taking into account that REE recovery is usually performed from solutions of mineral inorganic acids, used as leaching solutions for phosphogypsum or other REM-containing materials, the paper focuses on ytterbium recovery in the form of anionic complexes with Trilon B on weakly basic anion exchange resin D-403 from nitric acid solutions.

Experiment methodology. Static sorption examination. Examination of REE sorption was carried out from model solutions, containing anion complexes of ytterbium with Trilon B (EDTA 
ytterbiate ions), obtained by adding Trilon B to ytterbium nitrate solution with a precise mole ratio of $1: 1$ in accordance with the reaction stoichiometry [9].

$$
\mathrm{H}_{2} \mathrm{Tr}^{2-}+\mathrm{Yb}^{3+} \leftrightarrow[\mathrm{YbTr}]^{-}+2 \mathrm{H}^{+} .
$$

Variable concentrations method was used at $\mathrm{L} / \mathrm{S}$ ratio $=5$ (solution -20 , anion resin $-4 \mathrm{~cm}^{3}$ ), $\mathrm{pH}=3$ and constant ionic strength $I$, equal to $1 \mathrm{~mol} / \mathrm{kg}\left(\mathrm{NaNO}_{3}\right)$. Sorption was performed at temperatures $T$, equal to 298 and $343 \mathrm{~K}$ in the interval of ytterbium concentrations $0.1082-0.0056 \mathrm{~mol} / \mathrm{kg}$.

As an ion exchange resin, the authors utilized anionite D-403 in a nitrate form (China), which is a polystyrene chelate anionite with a divinylbenzene-styrol matrix and a functional group in the form of tertiary nitrogen atom with oxyhydrilic groups in positions $\beta, \gamma$ and $\delta$, which decrease the mobility of a lone-pair nitrogen electrons as a result of negative inductive effect [9]:<smiles>CCN(C)CC(O)C(O)C(O)C(O)CO</smiles>

The solution and anionite were mixed at the rate of $120 \mathrm{rpm}$ in a GFL thermostated cabinet (Germany) for 5-6 h until it reached equilibrium. Ytterbium concentration in the initial and equilibrium solutions was measured using spectrophotometric method with arsenazo (III) and X-ray fluorescence method on Epsilon 3 spectrometer (produced by PANalytical).

Dynamic sorption examination. In order to confirm the values of limiting sorption, saturation of D-403 anionite with EDTA ytterbiate ions was performed under dynamic conditions. The experiment took place in a sorption column with diameter of $1.2 \mathrm{~cm}$ and anionite layer height of $31.5 \mathrm{~cm}$, the mass of anionite was $11.3 \mathrm{~g}$. Solution containing $0.0398 \mathrm{~mol} / 1$ of EDTA ytterbiate ions was passed through the column at a rate of $1 \mathrm{ml} / \mathrm{min}$ using peristaltic pump LOIP LS-301 (JSC "Laboratory Equipment \& Instruments", Russia). On column exit the solution was sampled by $5 \mathrm{ml}$ until the breakthrough and by $10 \mathrm{ml}$ after the breakthrough until the initial concentration was reached.

Experiment results. Estimation of equilibrium constant, Gibbs free energy of ion exchange and total anionite capacity. Data obtained in the process of sorption at temperatures 298 and $343 \mathrm{~K}$ are presented in Table 1. Sorption value was calculated using formula

$$
q=\frac{\left(C_{0}-C_{\infty}\right) V}{m}
$$

where $C_{0}$ and $C_{\infty}$ are initial and equilibrium concentrations of complex ions in the solution, mol $/ \mathrm{kg}$; $V$ is volume, $\mathrm{ml} ; m$ is dry anionite mass, $\mathrm{g}$.

\begin{tabular}{|c|c|c|c|c|c|}
\hline \multicolumn{3}{|c|}{$298 \mathrm{~K}$} & \multicolumn{3}{|c|}{$343 \mathrm{~K}$} \\
\hline$C_{0}, \mathrm{~mol} / \mathrm{kg}$ & $C_{\infty}, \mathrm{mol} / \mathrm{kg}$ & $q, \mathrm{~mol} / \mathrm{kg}$ & $C_{0}, \mathrm{~mol} / \mathrm{kg}$ & $C_{\infty}, \mathrm{mol} / \mathrm{kg}$ & $q, \mathrm{~mol} / \mathrm{kg}$ \\
\hline 0.1082 & 0.0901 & 0.2786 & 0.1082 & 0.0822 & 0.4066 \\
\hline 0.0947 & 0.0768 & 0.2642 & 0.0947 & 0.0690 & 0.3950 \\
\hline 0.0863 & 0.0722 & 0.2587 & 0.0863 & 0.0634 & 0.3893 \\
\hline 0.0749 & 0.0607 & 0.2442 & 0.0749 & 0.0544 & 0.3791 \\
\hline 0.0678 & 0.0522 & 0.2322 & 0.0678 & 0.0425 & 0.3624 \\
\hline 0.0525 & 0.0392 & 0.2111 & 0.0525 & 0.0302 & 0.3392 \\
\hline 0.0433 & 0.0303 & 0.1936 & 0.0433 & 0.0225 & 0.3195 \\
\hline 0.0311 & 0.0204 & 0.1697 & 0.0311 & 0.0131 & 0.2838 \\
\hline 0.0173 & 0.0094 & 0.1311 & 0.0173 & 0.0040 & 0.2120 \\
\hline 0.0110 & 0.0048 & 0.1267 & 0.0110 & 0.0010 & 0.1784 \\
\hline 0.0079 & 0.0020 & 0.0778 & 0.0079 & 0.0004 & 0.1110 \\
\hline 0.0056 & 0.0009 & 0.0590 & 0.0056 & 0.0002 & 0.0853 \\
\hline
\end{tabular}


Sorption isotherms are presented in Fig.1.

In order to derive thermodynamic data, authors mathematically transformed the mass action law,

$$
K=\frac{q_{\mathrm{YbTr}^{-}} a_{\mathrm{NO}_{3}^{-}}}{q_{\mathrm{NO}_{3}^{-}} a_{\mathrm{YbTr}}}=\frac{q_{\mathrm{YbTr}^{-}}\left[\mathrm{NO}_{3}^{-}\right] \gamma_{\mathrm{NO}_{3}^{-}}}{q_{\mathrm{NO}_{3}^{-}}\left[\mathrm{YbTr}^{-}\right] \gamma_{\mathrm{YbTr}}}
$$

used in ion exchange equation

$$
R\left[\mathrm{NO}_{3}\right]+\mathrm{YbTr}^{-} \leftrightarrow R[\mathrm{YbTr}]+\mathrm{NO}_{3}^{-},
$$

where $K$ is the constant of ion exchange equilibrium; $q_{\mathrm{YbTr}^{-}}, q_{\mathrm{NO}_{3}^{-}}$are values of ion concentration in solid phase of the anionite,

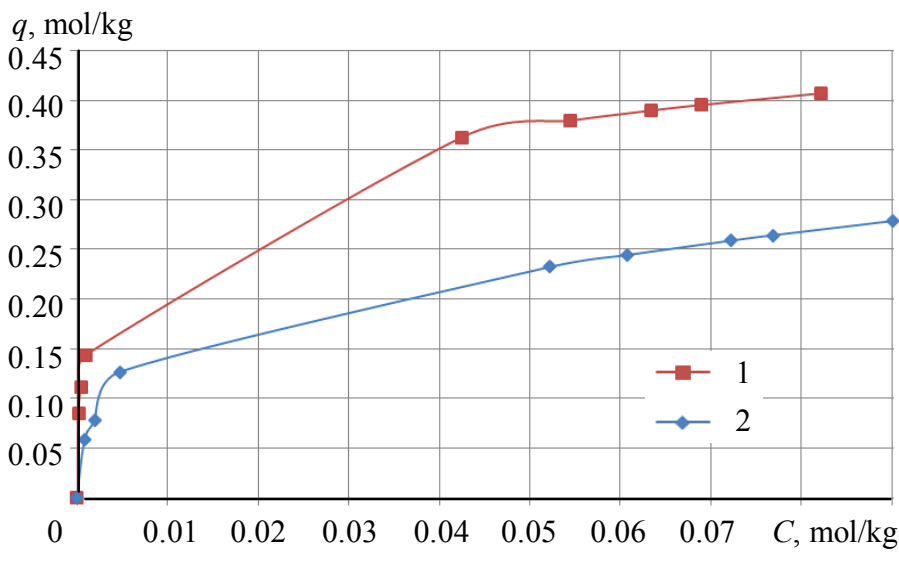

Fig.1. Sorption isotherms of ytterbium anion complexes with Trilon B on $\mathrm{D}-403$ anionite in nitrate form under $\mathrm{pH}=3$ and temperatures 298 and $343 \mathrm{~K}$ $1-343 ; 2-298 \mathrm{~K}$ $\mathrm{mol} / \mathrm{kg} ; a_{\mathrm{NO}_{3}^{-}}, a_{\mathrm{YbTr}^{-}}$indicate activity of nitrate and EDTA ytterbiate ions, $\mathrm{mol} / \mathrm{kg} ;\left[\mathrm{NO}_{3}^{-}\right],\left[\mathrm{YbTr}^{-}\right]$ are concentrations of nitrate and EDTA ytterbiate ions, mol $/ \mathrm{kg} ; \gamma_{\mathrm{NO}_{3}^{-}}, \gamma_{\mathrm{YbTr}^{-}}$are activity coefficients of nitrate and EDTA ytterbiate ions; $R$ is organic matrix of ion exchanger.

Assuming that limiting sorption is composed of equilibrium sorption values of nitrate and EDTA ytterbium ions,

$$
q_{\infty}=q_{\mathrm{NO}_{3}^{-}}+q_{\mathrm{YbTr}^{-}} \rightarrow q_{\mathrm{NO}_{3}^{-}}=q_{\infty}-q_{\mathrm{YbTr}^{-}},
$$

the mass action law can be converted to linear form, similar to Langmuir sorption isotherm

$$
\frac{1}{q_{\mathrm{YbTr}^{-}}}=\frac{1}{q_{\infty}}+\frac{\left[\mathrm{NO}_{3}^{-}\right] \gamma_{ \pm \mathrm{NaNO}_{3}}^{2}}{K q_{\infty}\left[\mathrm{YbTr}^{-}\right] \gamma_{ \pm \mathrm{NaYbTr}}^{2}}
$$

where $f(C)=\frac{\left[\mathrm{NO}_{3}^{-}\right] \gamma_{ \pm \mathrm{NaNO}_{3}}^{2}}{\left[\mathrm{YbTr}^{-}\right] \gamma_{ \pm \mathrm{NaYbTr}}^{2}}$ is $\mathrm{x}$-axis of concentration; $\frac{1}{q_{\mathrm{YbTr}^{-}}}$is y-axis of inverse sorption, $\gamma_{ \pm}$ are average ion coefficients of electrolyte activity, expressed through activity coefficients of individual ions:

$$
\begin{aligned}
& \gamma_{ \pm \mathrm{NaNO}_{3}}=\sqrt{\gamma_{\mathrm{Na}^{+}} \gamma_{\mathrm{NO}_{3}^{-}}} \rightarrow \gamma_{\mathrm{NO}_{3}^{-}}=\frac{\gamma_{ \pm \mathrm{NaNO}_{3}}^{2}}{\gamma_{\mathrm{Na}^{+}}}, \\
& \gamma_{ \pm \mathrm{NaYbTr}}=\sqrt{\gamma_{\mathrm{Na}^{+}} \gamma_{\mathrm{YbTr}^{-}}} \rightarrow \gamma_{\mathrm{YbTr}^{-}}=\frac{\gamma_{ \pm \mathrm{NaYbTr}^{2}}^{2}}{\gamma_{\mathrm{Na}^{+}}} .
\end{aligned}
$$

Average ion activity coefficients were estimated using reference data and mathematical description of dependence between activity coefficients and ionic strength of the solutions. Under given ionic strength, for $\mathrm{NaYbTr}$ compound, $\gamma_{ \pm}$was considered equal to $\mathrm{CH}_{3} \mathrm{COONa}$ due to strong dependency of activity coefficients upon ion charge and ionic strength of the solution, as well as weak dependency on anion individual character, including the complex ion. It is established that complex ions do not demonstrate any specific features in terms of activity coefficients as compared to simple electrolytes [4].

Taking into account the impact of temperature, activity coefficients were re-estimated using formula

$$
\lg \gamma_{ \pm, 343}=\frac{\mathrm{A}_{343}}{\mathrm{~A}_{298}} \lg \gamma_{ \pm, 298}
$$


where $\gamma_{ \pm, 343}$ and $\gamma_{ \pm, 298}$ are values of average ion activity coefficients at respective temperatures; $A_{343}$ and $\mathrm{A}_{298}$ are coefficients of Debye - Hückel equation for temperatures 343 and $298 \mathrm{~K}$, respectively $\left(\mathrm{A}_{343}=0.5562, \mathrm{~A}_{298}=0.5107[1]\right)$.

Calculated and experimentally obtained data for mathematical description of linear-form sorption isotherms of ytterbium on D-403 anionite from nitrate solutions at temperatures 298 and $343 \mathrm{~K}$ are presented in Table 2 .

Table 2

Data for plotting linear-form sorption isotherms of EDTA ytterbiate ions on anionite

\begin{tabular}{c|c|c|c|c|c|c}
\hline $\begin{array}{c}1 / q, \\
\mathrm{~kg} / \mathrm{mol}\end{array}$ & $I, \mathrm{~mol} / \mathrm{kg}$ & $\begin{array}{c}{\left[\mathrm{NO}_{3}^{-}\right],} \\
\mathrm{mol} / \mathrm{kg}\end{array}$ & $\begin{array}{c}{\left[\mathrm{YbTr}^{-}\right],} \\
\mathrm{mol} / \mathrm{kg}\end{array}$ & $\gamma_{ \pm \mathrm{NaYbTr}}$ & $\gamma_{ \pm \mathrm{NaNO}_{3}}$ & $f(C)$ \\
\hline \multicolumn{7}{|c}{$298 \mathrm{~K}$} \\
3.5890 & 1.1082 & 1.3328 & 0.0901 & 0.7677 & 0.5183 & 6.7415 \\
3.7856 & 1.0947 & 1.2923 & 0.0768 & 0.7670 & 0.5214 & 7.7740 \\
3.8652 & 1.0863 & 1.2654 & 0.0722 & 0.7666 & 0.5234 & 8.1758 \\
4.0942 & 1.0749 & 1.2312 & 0.0607 & 0.7660 & 0.5261 & 9.5645 \\
4.3064 & 1.0678 & 1.2105 & 0.0522 & 0.7656 & 0.5278 & 11.0200 \\
7.8927 & 1.0110 & 1.0358 & 0.0048 & 0.7628 & 0.5431 & 110.3377 \\
12.8593 & 1.0079 & 1.0262 & 0.0020 & 0.7627 & 0.5440 & 262.7363 \\
& & & & & & \\
2.4594 & 1.1082 & 1.3520 & 0.0822 & 0.7474 & 0.4880 & 7.014542 \\
2.5318 & 1.0947 & 1.3111 & 0.0690 & 0.7462 & 0.4912 & 8.23391 \\
2.5689 & 1.0863 & 1.2831 & 0.0634 & 0.7455 & 0.4935 & 8.871151 \\
2.6380 & 1.0749 & 1.2463 & 0.0544 & 0.7446 & 0.4965 & 10.1794 \\
2.7592 & 1.0678 & 1.2299 & 0.0425 & 0.7440 & 0.4979 & 12.95437 \\
2.9477 & 1.0525 & 1.1810 & 0.0302 & 0.7427 & 0.5021 & 17.89694 \\
5.6054 & 1.0110 & 1.0434 & 0.0010 & 0.7393 & 0.5150 & 495.4003 \\
9.0053 & 1.0079 & 1.0313 & 0.0004 & 0.7391 & 0.5162 & 1125.44
\end{tabular}

Linear forms of sorption isotherms are presented in Fig.2.

Using equations of linear form approximation (Fig.2), values for equilibrium constants, and Gibbs free energy, total anionite capacity were calculated, as well as limiting sorption of a complex EDTA ytterbiate ion (Fig.3).

Thermodynamic and sorption characteristics are presented below:

$\begin{array}{ccccccc}T, \mathrm{~K} & \text { Approximating equation } & \text { Correlation coefficient } R^{2} & K & \Delta_{r} G_{T}^{0}, \mathrm{~kJ} / \mathrm{mol} & q_{\infty}, \mathrm{mol} / \mathrm{kg} & q_{\mathrm{YbTr}}, \mathrm{mol} / \mathrm{kg} \\ 298 & y=0.0355 x+3.6573 & 0.9956 & 103.02 \pm 5.15 & -11.48 \pm 5.74 & 0.27 \pm 0.01 & 0.28 \pm 0.01 \\ 343 & y=0.0058 x+2.6024 & 0.9961 & 448.69 \pm 22.43 & -17.42 \pm 8.71 & 0.38 \pm 0.02 & 0.41 \pm 0.02\end{array}$

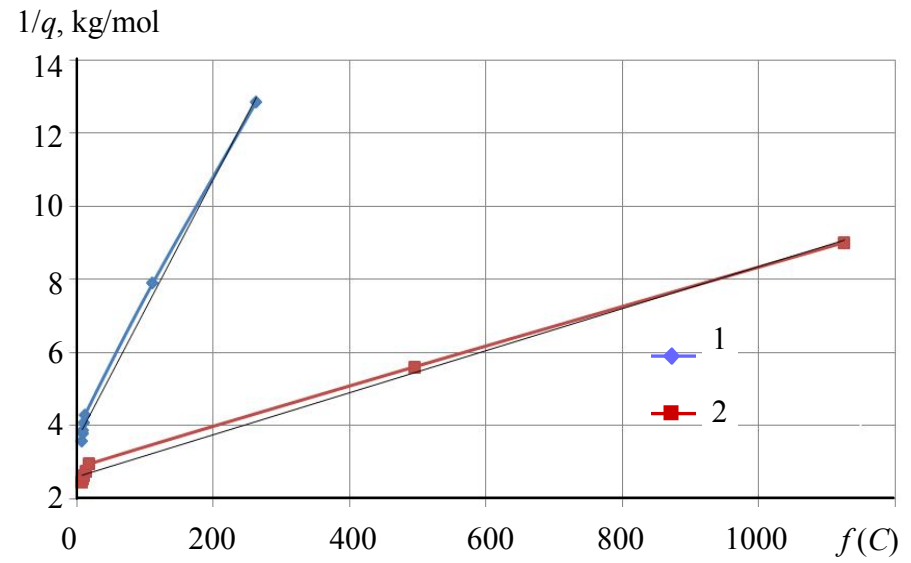

Fig.2. Linear forms of sorption isotherms for EDTA ytterbiate ions on D-403 anionite at temperatures 298 and $343 \mathrm{~K}$

$$
1-298 ; 2-343 \mathrm{~K}
$$

Estimation of sorption enthalpy and entropy. Basing on obtained values of equilibrium constants in the temperature interval 298-343 K, enthalpy of ion exchange was calculated using isobar equation

$$
\Delta H_{\left(T_{2}-T_{1}\right)}^{0}=R \frac{T_{1} T_{2}}{T_{2}-T_{1}} \ln \frac{K_{2}}{K_{1}},
$$

where $T_{1}$ and $T_{2}$ are temperatures of sorption process, $K_{1}$ and $K_{2}$ are constants of ion exchange equilibrium at respective temperatures. Likewise, ion exchange entropy was estimated:

$$
\Delta S_{T}^{0}=\frac{1}{T}\left(\Delta H_{T}^{0}-\Delta G_{T}^{0}\right) .
$$


The following values were obtained:

$$
\begin{gathered}
\Delta H_{\left(T_{2}-T_{1}\right)}^{0}=13.88 \pm 6.94 \mathrm{~kJ} / \mathrm{mol}, \\
\Delta S_{298}^{0}=85.08 \pm 4.25 \mathrm{~J} / \mathrm{mol} \cdot \mathrm{K}, \\
\Delta S_{343}^{0}=91.23 \pm 4.56 \mathrm{~J} / \mathrm{mol} \cdot \mathrm{K} .
\end{gathered}
$$

Estimation of total dynamic exchange capacity (TDEC) and dynamic exchange capacity (DEC). According to results, presented in Fig.2, limiting sorption of a complex ion under static conditions at $298 \mathrm{~K}$ was estimated at

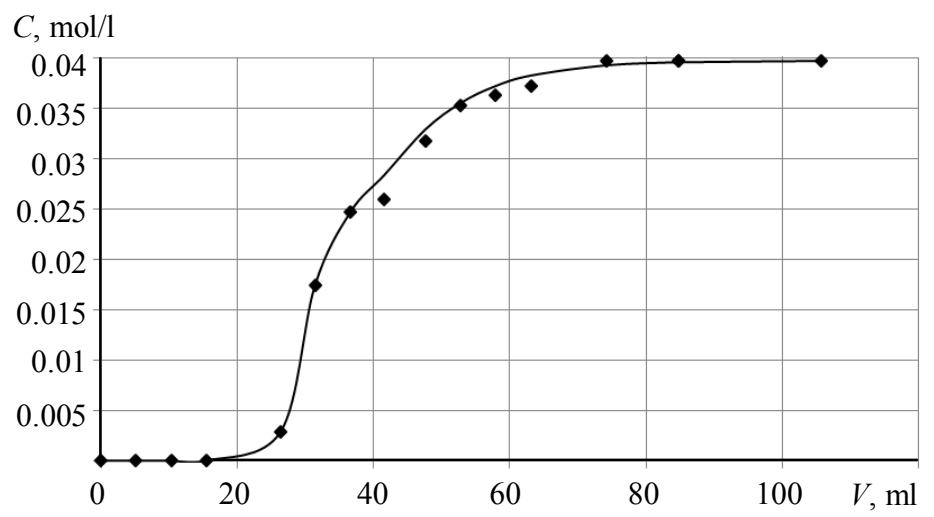

Fig.3. Output curve of EDTA ytterbiate ion sorption on D-403 anionite at $\mathrm{pH}=3$ and $T=298 \mathrm{~K}$ $0.279 \pm 0.014 \mathrm{~mol} / \mathrm{kg}$. Sorption curve for dynamic conditions is presented in Fig.3.

TDEC and DEC values were calculated using formulas:

$$
\begin{gathered}
\text { TDEC }=\frac{1}{m} \sum_{C_{n}=0}^{C_{n}=C_{0}}\left(V_{n+1}-V_{n}\right)\left(C_{0}-C_{n}\right) ; \\
\text { DEC }=\frac{1}{m} C_{0} V_{\mathrm{br}},
\end{gathered}
$$

where $m$ is sorbent mass, g; $C_{0}$ and $C_{n}$ are initial and current cerium concentrations on column exit, $\mathrm{mg} / \mathrm{ml} ; V_{n+1}, V_{n}$ are volumes of solution, corresponding to cerium concentrations on column exit $C_{n+1}$ and $C_{n}, \mathrm{ml} ; V_{\mathrm{br}}$ is the volume of solution before the breakthrough, $\mathrm{ml}$.

TDEC and DEC were estimated at $0.12 \pm 0.01$ and $0.09 \pm 0.01 \mathrm{~mol} / \mathrm{kg}$, respectively.

Discussion of experimental results. According to calculated Gibbs free energy of ion exchange at temperature $298 \mathrm{~K}$, EDTA ytterbiate ions have greater chemical affinity to the solid phase of ion exchange resin than light-group REEs:

$\begin{array}{ccccc}\text { EDTA REM ion } & {[\mathrm{CeTr}]^{-}} & {[\mathrm{YTr}]^{-}} & {[\mathrm{ErTr}]^{-}} & \left.{ }^{\mathrm{YbTr}}\right]^{-} \\ -\Delta_{r} G_{298}^{0}, \mathrm{~kJ} / \mathrm{mol} & 0.15 \pm 0.01 & 4.82 \pm 0.15 & 9.24 \pm 4.62 & 11.48 \pm 5.74\end{array}$

It happens due to the specific character of ligand coordination against REE ion of light and heavy groups [2]. The inner sphere of [YbTr $]^{-}$and [ErTr] ${ }^{-}$complexes is composed of two nitrogen atoms and four carboxyl groups, whereas $[\mathrm{CeTr}]^{-}$and $[\mathrm{YTr}]^{-}$complexes contain two nitrogen atoms and only three carboxyl groups (Fig.4). An increase in effective negative charge of complex erbium and ytterbium ions leads to an increase in electrostatic interaction with the matrix of ion exchange resin. As a result, with diminishing atomic radius and elevating effective charge of the complex, chemical affinity to the solid phase of anion exchange resin increases.
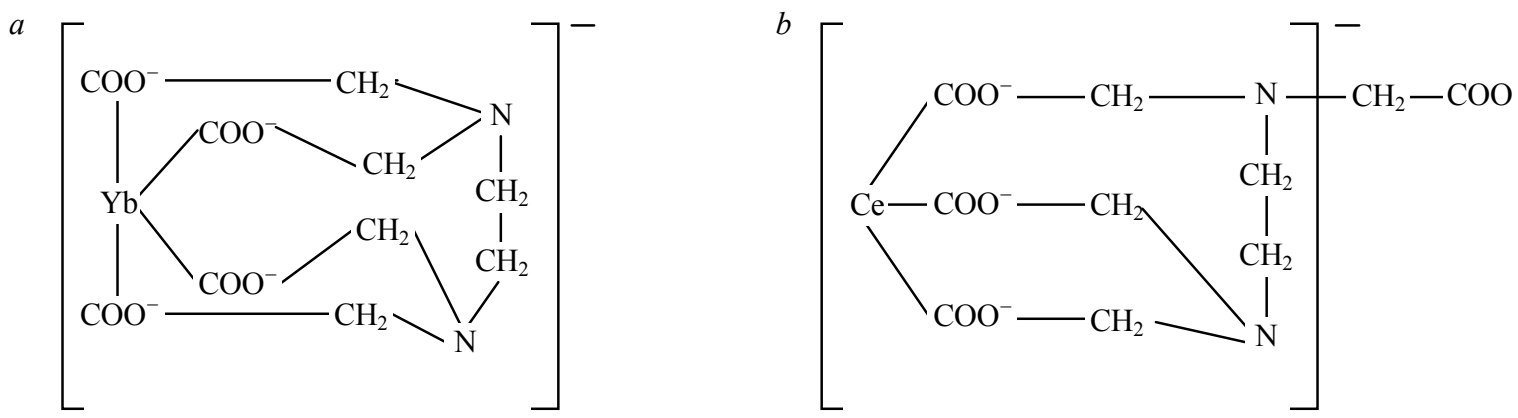

Fig.4. Coordination compound of ytterbium $(a)$ and cerium $(b)$ with Trilon B 
Decreasing Gibbs free energy in the array 'cerium-erbium-ytterbium' correlates with lanthanide contraction, diminishing atomic radius and elevating effective charge of the complex, which leads to greater affinity, intensification of electrostatic interaction with anion exchange resin and higher selectivity.

Limiting sorption value of complex ion agrees with the values of total anionite capacity at both temperatures. With rising temperature the sorption value increases, as the equilibrium shifts in the direction of nitrate ion displacement from the matrix of ion exchange resin by EDTA ytterbiate ions.

Enthalpy value is positive, but the defining factor of decreasing Gibbs energy $\Delta G_{T}^{0}<0$ in the course of ion exchange with rising temperature is an entropy criterion. Obtained thermodynamic data characterize selectivity of ion exchange between EDTA ytterbiate ions in the REE array and $\mathrm{NO}_{3}^{-}$on the surface of ion exchanger. The fact that complex ion sorption does not reach the value of limiting sorption is explained by the large geometric size of EDTA ytterbiate ion.

Conclusion. The paper examined ytterbium sorption in the form of anionic complexes with Trilon B from nitrate solutions at constant ionic strength of $1 \mathrm{~mol} / \mathrm{kg}, \mathrm{pH}=3, \mathrm{~L} / \mathrm{S}$ ratio $=5$ and temperatures 298 and $343 \mathrm{~K}$ on weakly basic anion exchange resin D-403.

Obtained values of limiting sorption of complex EDTA ytterbiate ion equal $0.28 \pm 0.01$ at temperature $298 \mathrm{~K}$ and $0.41 \pm 0.02 \mathrm{~mol} / \mathrm{kg}$ at $343 \mathrm{~K}$ under static conditions, TDEC $=0.12 \pm 0.01$ and $\mathrm{DEC}=0.09 \pm 0.01 \mathrm{~mol} / \mathrm{kg}$ under dynamic conditions.

Estimations were made for total anionite capacity at temperatures 298 and $343 \mathrm{~K}$ : $\mathrm{L}_{\infty}=0.27 \pm 0.01$ and $\mathrm{L}_{\infty}=0.38 \pm 0.02 \mathrm{~mol} / \mathrm{kg}$, respectively.

Mathematical transformation of mass action law was performed, as it was converted to a linear form similar to Langmuir equation, the graphic solution of which allowed to calculate thermodynamic parameters of ion exchange process.

Equilibrium constants and Gibbs free energy of ion exchange at temperatures 298 and $343 \mathrm{~K}$ were $K_{298}=103.02 \pm 5.15 ; \Delta_{r} G_{298}^{0}=11.45 \mathrm{~kJ} / \mathrm{mol} ; K_{343}=448.69 \pm 22.43$ and $\Delta_{r} G_{343}^{0}=-17.42 \pm$ $\pm 8.71 \mathrm{~kJ} / \mathrm{mol}$.

Using Gibbs free energy values, enthalpy and entropy of ion exchange process were calculated: $\Delta H_{\left(T_{2}-T_{1}\right)}^{0}=13.88 \pm 6.94 \mathrm{~kJ} / \mathrm{mol}, \Delta S_{298}^{0}=85.08 \pm 4.25, \Delta S_{343}^{0}=91.23 \pm 4.56 \mathrm{~J} / \mathrm{mol} \cdot \mathrm{K}$. Obtained thermodynamic data characterize the feasibility of using D-403 anion exchange resin to recover REEs and separate them into individual components.

\section{REFERENCES}

1. Vasilev V.P. Thermodynamic Properties of Electrolyte Solutions. Moscow: Vysshaya shkola, 1982, p. 320 (in Russian).

2. Martynenko L.I. Specifics of Rare Earth Elements (III) Complex Formation. Uspekhi khimii. 1991. Vol. 60. Iss. 9. p. 19691998 (in Russian).

3. Global Market of Rare Earth Metals and Compounds 2019-2025 (9th edition): Analytical Study; Research Group Specializing on the Markets of Raw Materials, Metals and Associated Products. International Metallurgical Research Group. 2019, p. 104. URL: https://docplayer.ru/134894766-Mirovoy-rynok-redkozemelnyh-metallov-i-soedineniy-9-izdanie.html (date of access 27.01.2020) (in Russian).

4. Mironov I.V. Environmental Effect and Complex Formation in Electrolyte Solutions. Novosibirsk: INKh SO RAN, 2003, p. 240 (in Russian).

5. Ivanik S.A., Ilyukhin D.A. Flotation extraction of elemental sulfur from gold-bearing cakes. Journal of Mining Institute. 2020. Vol. 242, p. 202-208. DOI: 10.31897/PMI.2020.2.202

6. Sizyakov V.M., Litvinova T.E., Brichkin V.N., Fedorov A.T. Modern physicochemical equilibrium description in $\mathrm{Na}_{2} \mathrm{O}-\mathrm{Al}_{2} \mathrm{O}_{3}-\mathrm{H}_{2} \mathrm{O}$ system and its analogues. Journal of Mining Institute. 2019. Vol. 237, p. 298-306. DOI: 10.31897/PMI.2019.3.298

7. Callura J.C., Perkins K.M., Baltrus J.P., Washburn N.R., Dzombak D.A., Karamalidis A.K. Adsorption kinetics, thermodynamics, and isotherm studies for functionalized lanthanide-chelating resins. Journal of Colloid and Interface Science. 2019. Vol. 557, p. 465-477. DOI: 10.1016/j.jcis.2019.08.097

8. Cui H., Feng X., Sh J., Liu W., Yan N., Rao G., Wang W. A facile process for enhanced rare earth elements separation from dilute solutions using N, N-di(2-ethylhexyl)-diglycolamide grafted polymer resin. Separation and Purification Technology. 2020. Vol. 234. 116096. DOI: 10.1016/j.seppur.2019.116096

9. Cheremisina O.V., Ponomareva M.A., Sagdiev V.N. Thermodynamic Characteristics of Sorption Extraction and Chromatographic Separation of Anionic Complexes of Erbium and Cerium with Trilon B on Weakly Basic Anionite. Russian Journal of Physical Chemistry A. 2016. Vol. 90 (3), p. 664-670. DOI: 10.1134/S0036024416030079 
10. Manousi N., Gomez-Gomez B., Madrid Y., Deliyanni E.A., Zachariadis G.A. Determination of rare earth elements by inductively coupled plasma-mass spectrometry after dispersive solid phase extraction with novel oxidized graphene oxide and optimization with response surface methodology and central composite design. Microchemical Journal. 2020. Vol. 152.104428. DOI: $10.1016 /$ j.microc.2019.104428

11. Batchu N.K., Dewulf B., Riaño S., Binnemans K. Development of a solvometallurgical process for the separation of yttrium and europium by Cyanex 923 from ethylene glycol solutions. Separation and Purification Technology. 2020. Vol. 235. 116193. DOI: 10.1016/j.seppur.2019.116193

12. Turanov A.N., Karandashev V.K., Baulin V.E., Baulin D.V., Khvostikov V.A. Extraction of Rare-Earth Elements (III) from Nitric Acid Solutions with Diethyl 2-[(Diphenylphosphoryl)methoxy]-5-ethylphenylphosphonate. Russian Journal of Inorganic Chemistry. 2019. Vol. 64(10), p. 1297-1303. DOI: 10.1134/S0036023619100164

13. Maria L., Cruz A., Carretas J.M., Monteiro B., Galinha C., Gomes S.S., Araújo M.F., Paiva I., Marçalo J., Leal J.P. Improving the selective extraction of lanthanides by using functionalised ionic liquid. Separation and Purification Technology. 2020. Vol. 237. 116354. DOI: 10.1016/j.seppur.2019.116354

14. Gedgagov E.I., Zakharyan S.V., Sinyanskaya O.M., Zakharyan D.V. Removal of Impurities from Saturated Ion-Exchange Resins by Frontal-Gradient Purification in Schemes for Recovery of Nonferrous, Rare, and Rare Earth Metals. Theoretical Foundations of Chemical Engineering. 2018. Vol. 52 (5), p. 920-927. DOI: 10.1134/S0040579518050111

15. Kuskov V.B., Kuskova Y.V. Research of physical and mechanical properties of briquettes, concentrated from loose highgrade iron ores. 17th International Multidisciplinary Scientific GeoConference SGEM 2017, 29 June - 5 July 2017. Vol. 17. Iss. 11, p. 1011-1016. DOI: 10.5593/sgem2017/11/S04.129

16. Bailey G., Joyce P.J., Schrijvers D., Schulze R., Sylvestre A.M., Sprecher B., Vahidi E., Dewulf W., Van Acker K. Review and new life cycle assessment for rare earth production from bastnäsite, ion adsorption clays and lateritic monazite. Resources, Conservation and Recycling. 2020. Vol. 155. 104675. DOI: 10.1016/j.resconrec.2019.104675

17. Xiong X.H., Tao Y., Yu Z.W., Yan L.X., Sun L.J., Fan Y.L., Luo F. Selective extraction of thorium from uranium and rare earth elements using sulfonated covalent organic framework and its membrane derivate. Chemical Engineering Journal. 2020. Vol. 384. 123240. DOI: 10.1016/j.cej.2019.123240

18. Swain N., Mishra S., Acharya M.R. Hydrometallurgical route for recovery and separation of samarium (III) and cobalt (II) from simulated waste solution using tri-n-octyl phosphine oxide - A novel pathway for synthesis of samarium and cobalt oxides nanoparticles. Journal of Alloys and Compounds. 2020. Vol. 815. 152423. DOI: 10.1016/j.jallcom.2019.152423

Authors: Olga V. Cheremisina, Professor, Head of Department, Cheremisina_OV@pers.spmi.ru (Saint Petersburg Mining University, Saint Petersburg, Russia), Elizaveta Cheremisina, PhD, Post-Doc High Temperature Metallurgy Area, elizaveta.cheremisina@k1-met.com (K1-MET GmbH, Linz, Austria), Maria A. Ponomareva, Assistant Lecturer, Ponomareva_MA@pers.spmi.ru (Saint Petersburg Mining University, Saint Petersburg, Russia), Aleksander T. Fedorov, Assistant Lecturer, bers10@bk.ru (Saint Petersburg Mining University, Saint Petersburg, Russia).

The paper was received on 27 January, 2020.

The paper was accepted for publication on 22 May, 2020. 